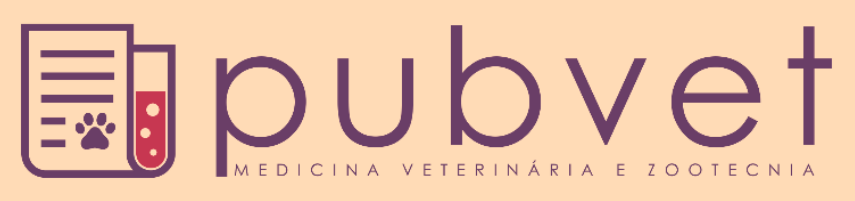

https://doi.org/10.31533/pubvet.v13n3a283.1-7

\title{
Ocorrência da leucemia felina e imunodeficiência felina em gatos domésticos do município de Mineiros, Goiás
}

\author{
Marinara $\operatorname{Lemos}^{1}{ }^{\bullet}$, Juciene Silva Oliveira ${ }^{1}$, Sabrina Jesus Almeida ${ }^{1} \bullet$, Priscila Gomes de

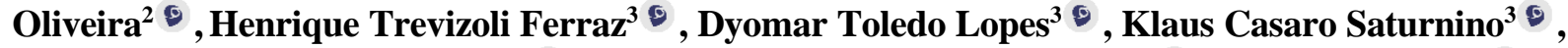 \\ Karla Irigaray Nogueira Borges ${ }^{4}$, Dirceu Guilherme de Souza $\operatorname{Ramos}^{3}$, Ísis Assis Braga ${ }^{* *}$ \\ ${ }^{I}$ Graduada em Medicina Veterinária pelo Centro Universitário de Mineiros UNIFIMES. Mineiros-GO Brasil. \\ ${ }^{2}$ Mestranda em Biociência Animal pela Universidade Federal de Goiás, UFG. Jataí-GO, Brasil. \\ ${ }^{3}$ Professor Doutor da Universidade Federal de Goiás, UFG. Jataí-GO, Brasil. \\ ${ }^{4}$ Professora Especialista do Centro Universitário de Mineiros UNIFIMES. Mineiros-GO Brasil. \\ ${ }^{5}$ Professora Doutora do Centro Universitário de Mineiros UNIFIMES. Mineiros-GO Brasil. \\ *Autor para correspondência, E-mail: isis@ unifimes.edu.br
}

Resumo. O vírus da leucemia felina (FeLV) e o vírus da imunodeficiência felina (FIV), pertencem a família Retroviridae, e são agentes importantes, visto que acometem o sistema imunológico de felinos. Objetivou-se avaliar a ocorrência de FIV e FeLV em gatos do município de Mineiros, no estado de Goiás escolhidos aleatoriamente. Foram avaliados randomicamente 72 felinos do município de Mineiros através do teste cromatográfico ALERETM FIV Ac / FeLV Ag TEST KIT, e destes 12,5\% demostraram reagentes ao FIV e $2,77 \%$ ao FeLV, sendo observado uma maior frequência da infecção em gatos machos, adultos e sem raça definida, que tinham livre acesso à rua, fator muito relevante na propagação de FIV e FeLV, dada a sua forma de transmissão. Estudos visando o inquérito epidemiológico destas enfermidades virais na região são escassos, contudo os dados obtidos neste, fornecem informações relevantes aos profissionais da cidade, para que os mesmos possam orientar os proprietários, buscando controle das enfermidades nos animais.

Palavras chave: FeLV, FIV, Felinos, Imunocromatografia

\section{Occurrence of feline leukemia feline immunodeficiency in domestic cats from the municipality of Mineiros, Goiás}

\begin{abstract}
The feline leukemia virus (FeLV) and the feline immunodeficiency virus (FIV) belong to the Retroviridae family and are important agents as they affect the immune system of felines. The objective of this study was to evaluate the occurrence of FIV and FeLV in cats from the municipality of Mineiros, in the Goiás state, randomly selected. Seventy-two cats from the municipality of Mineiros were randomly evaluated using the ALERE $^{\text {TM }}$ FIV Ac / FeLV Ag TEST KIT chromatographic test, and of these 12.5\% showed reagents to FIV and $2.77 \%$ to FeLV, with a higher frequency of infection in male cats, both adults and non-defined, who had free access to the street, which is a very relevant factor in the spread of FIV and FeLV, given their mode of transmission. Studies on the epidemiological investigation of these viral diseases in the region are scarce, but the data obtained in this area provide relevant information to the city's professionals, so that they can guide the owners, seeking control of the diseases in the animals.
\end{abstract}

Keywords: FeLV, FIV, Cats, Immunochromatography. 


\title{
Prevalencia de Leucemia felina e inmunodeficiencia felina en gatos domésticos del municipio de Mineiros, Goiás.
}

\begin{abstract}
Resumen. El virus de la leucemia felina (FeLV) y el virus de inmunodeficiencia felina (FIV), pertenecen a la familia Retroviridae, y son agentes importantes, ya que acomete el sistema inmunológico de felinos. Se objetivó evaluar la ocurrencia de FIV y FeLV en gatos del municipio de Mineiros, en el estado de Goiás escogidos aleatoriamente. Se evaluaron aleatoriamente 72 felinos del municipio de Mineiros a través del ensayo cromatográfico

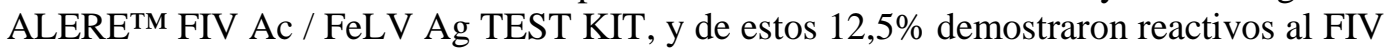
y el $2,77 \%$ al FeLV, siendo observado una mayor frecuencia de la infección en gatos machos, adultos y sin raza definida, que tenían libre acceso a la calle, que es un factor muy relevante en la propagación de FIV y FeLV, dada su forma de transmisión. Los estudios visando la encuesta epidemiológica de estas enfermedades virales en la región son escasos, sin embargo, los datos obtenidos en éste proporcionan informaciones relevantes a los profesionales de la ciudad, para que los mismos puedan orientar a los propietarios, buscando control de las enfermedades en los animales.
\end{abstract}

Palabras clave: FeLV, FIV, Gatos, Inmunocromatografía

\section{Introdução}

Atualmente o número de gatos vem crescendo na população de animais de companhia, e com isso doenças importantes devem ser cada vez mais estudadas. Como os vírus da imunodeficiência felina (FeLV) e da leucemia felina (FIV), que pertencem a família Retroviridae, e acometem felinos em todo o mundo (Lutz, 1990).

No Brasil, já foram detectados pelas pesquisas sorológicas e moleculares, em gatos domésticos domiciliares e de rua, nos estados de São Paulo, Rio de Janeiro, Rio Grande do Sul e Minas Gerais, com prevalências que podem variar entre $2,0 \%$ a $37,5 \%$ e de $8,0 \%$ a $63,0 \%$ para FIV e FeLV, respectivamente (Caldas et al., 2000; Souza et al., 2002). De acordo com Hartmann (2012) estes agentes etiológicos são responsáveis por causar efeitos imunossupressores e debilitantes, predispondo o animal a diversas doenças secundárias (Diehl \& Hoover, 1992; Ogilvie et al., 1988). Com esse sentido, a investigação desses vírus se torna fundamental na abordagem clínica dos felinos (Nelson \& Couto, 2015). A doença ocorre em gatos de qualquer sexo ou raça, apesar da ocorrência ser menor em gatos de raça, já que estes animais permanecem mais tempo no interior do domicílio (Greene, 2005). A incidência é maior em animais com faixa etária entre 1 a 5 anos e em locais com grande quantidade de felinos, como os gatis e abrigos (Teixeira et al., 2007). Segundo Nelson \& Couto (2015) o tratamento em gatos que são portadores destas retroviroses é inespecífico, sendo assim é importante estabelecer uma conduta terapêutica e um preciso diagnóstico que vise controlar o aparecimento de infecções secundárias (Teixeira et al., 2007). Com isso, visa-se obter dados epidemiológicos das enfermidades e verificar a ocorrência de infecção por FIV e FeLV em gatos do município de Mineiros, GO, imunoensaio cromatografico a fim de contribuir com os profissionais da área, para que os mesmos possam orientar os proprietários dos felinos, buscando controlar a doença nestes animais.

\section{Material e métodos}

Durante o período de março a agosto de 2017, forma colhidas amostras sanguíneas de 72 felinos domésticos escolhidos de forma aleatória. As amostras foram colhidas em diversas localidades do município de Mineiros e analisadas para detecção simultânea e qualitativa dos anticorpos $\operatorname{IgG}$ do vírus da FIV e antígenos (p27) do vírus da FeLV. A coleta de sangue total foi realizada pela venopunção da jugular externa em tubos a vácuo com EDTA (etilenodiaminotetracético), na ocasião foram abordadas questões referentes à idade, sexo, raça, acesso à rua. Esta pesquisa foi aprovada pela Comissão de Ética no Uso de Animais (CEUA), do Centro Universitário de Mineiros, sob o nº de Protocolo 15/2017.

As amostras sanguíneas foram analisadas utilizando o ensaio imunocromatográfico ALERETM FIV Ac/FeLV Ag TEST KIT, de acordo com as normas do fabricante. No qual, com o tubo capilar que acompanha o teste foi adicionado uma gota $(10 \mu \mathrm{L})$ de sangue total (podendo ser utilizado também 
somente o plasma ou soro) em cada orifício do cassete juntamente com 2 gotas de tampão. Em seguida, observou-se o momento em que o teste começou a reagir e demostrar uma cor rosa se movendo através da janela de resultado no centro do dispositivo e após 10 minutos foi realizada a interpretação do teste pelo aparecimento ou não de linhas coloridas.

\section{Resultados e discussão}

Dos 72 animais avaliados pelo teste imune ensaio cromatográfico, $9(12,5 \%)$ apresentaram resultado positivo para a presença de anticorpos anti-FIV e $2(2,77 \%)$ positivo para o antígeno p27 da FeLV. Sendo considerados positivos os resultados para FIV a presença de duas linhas coloridas (C e T), no teste FIV e somente uma linha controle (C) no teste FeLV. E positivos para FeLV os resultados com a presença de duas linhas coloridas (C e T), no teste FeLV e somente uma linha controle (C) no teste FIV. Dos animais positivos para FIV, todos eram machos e sem raça definida, em relação à idade, $2(2,7 \%)$ tinham dois anos, $1(1,3 \%)$ com três anos de idade, $2(2,7 \%)$ com quatro anos e $4(5,5 \%)$ entre seis a dez anos de idade. Todos os positivos para FeLV eram machos sendo $1(1,3 \%)$ com seis meses de idade e 1 $(1,3 \%)$ com três anos (Tabela 1$)$.

Considerando o estilo de vida dos gatos do grupo FIV positivo, $9(12,5 \%)$ dos animais tinham acesso à rua e no FeLV positivo 2 (2,77\%) dos animais também tinham acesso à rua (Tabela 1).

Tabela 1. Gatos positivos para o vírus da imunodeficiência felina (FIV), e o vírus da leucemia felina (FeLV) segundo o sexo, faixa etária, definição racial e acesso à rua, em uma população de 72 animais do município de Mineiros-GO

\begin{tabular}{lccc}
\hline Variáveis & Amostragem populacional & FIV & FeLV \\
\hline Sexo & & & $2(2,77 \%)$ \\
Macho & $44(61,1 \%)$ & $9(12,5 \%)$ & $0(0 \%)$ \\
\hline Fêmea & $28(38,8 \%)$ & $0(0 \%)$ & $1(1,3 \%)$ \\
\hline 2 meses-2,5 anos & & & $1(1,3 \%)$ \\
3 anos & $49(68 \%)$ & $2(2,7 \%)$ & $0(0 \%)$ \\
4 anos & $6(8,3 \%)$ & $1(1,3 \%)$ & $0(0 \%)$ \\
$6-10$ anos & $10(13,8 \%)$ & $2(2,7 \%)$ & $2(2,77)$ \\
\hline Definição racial & $7(9,7 \%)$ & $4(5,5 \%)$ & $0(0 \%)$ \\
\hline SRD & & & $2(12,5 \%)$ \\
Raça definida & $65(90 \%)$ & $0(0 \%)$ & $0(0 \%)$ \\
\hline Acesso à rua & $7(9,7 \%)$ & $9(12,5 \%)$ & $0(0 \%)$ \\
\hline Sim & & & \\
Não & $55(76,3 \%)$ & $17(23,6 \%)$ & \\
\hline SRD - Semia & &
\end{tabular}

SRD - Sem raça definida

Neste estudo a ocorrência de gatos infectados com FeLV testados pelo teste imune ensaio cromatográfico foi de $2,77 \%$. Estes resultados indicam uma ocorrência semelhante de FeLV como a descrita por outros autores, que investigaram a presença do vírus com taxas variando de 2,3\% a 38,3\% em diversos países (Arjona et al., 2000; Costa et al., 2000; Dorny et al., 2002; Levy et al., 2006; Meinerz et al., 2010; Solano et al., 2007; Souza et al., 2002; Yilmaz et al., 2000). Entretanto, deve ser levado em consideração que essa diferença nos resultados, pode ocorrer devido aos animais utilizados nessa pesquisa serem domiciliados e a amostragem de animais utilizados nas demais pesquisas serem provenientes de abrigos, gatis ou hospitais, consequentemente gerando uma frequência maior.

$\mathrm{Na}$ Costa Rica a prevalência encontrada foi de 16,7\% (Blanco et al., 2009), 30,4\% na Espanha (Arjona et al., 2000), 7,1\% em Portugal (Duarte et al., 2010). No Brasil, o FeLV pode ser encontrado com 47\% de prevalência em Minas Gerais (Coelho et al., 2008), 38,3\% no Rio Grande do Sul (Meinerz et al., 2010), 12\% em São Paulo (Junqueira-Jorge, 2005). Em Cuiabá, estado do Mato Grosso, Poffo (2012) relata ocorrência de 4,49\%. A ocorrência de animais positivos para FIV nesta pesquisa foi de $12,5 \%$, o que corrobora com os resultados de outras pesquisas. No Brasil, a sorologia detectou ocorrência de FIV com frequência variando entre 2,66\% em Minas Gerais (Caxito et al., 2003), em São Paulo variou de 11,7\% e 14,7\% (Reche Junior et al., 1997), 5,63\% em Araçatuba (Vicente Sobrinho et 
al., 2011), 37,5 \% no Rio Grande do Sul (Teixeira et al., 2007) e 12,35\% em Cuiabá (Poffo, 2012). As prevalências de FIV no mundo podem variar de 1\% a 44\% (Teixeira et al., 2007). Em outro estudo realizado em Belo Horizonte, de animais capturados na rua, a ocorrência foi de 4,14\% para FIV e 32,5\% para o FeLV, tendo um valor inferior de FIV comparado a outras pesquisas, e mais elevado de FeLV, podendo estar influenciada pela caracterização das populações que foram analisadas (Teixeira et al., 2007). No Hospital Veterinário da Universidade Federal Rural do Semi Árido - UFERSA (Mossoró, Rio Grande do Norte, Brasil) foi realizado um estudo em que trinta e nove felinos (24\%) tiveram resultado reagente para FIV e apenas um gato $(0,6 \%)$ foi reagente para FeLV, o qual também estava coinfectado com o FIV, como ocorrido neste estudo, haja vista que um $(1,3 \%)$ dos felinos infectados com FelV, estava coinfectado com FIV (Barros et al., 2017).

Nos grupos positivos de FIV e FeLV, o sexo dos gatos infectados era masculino, e a maioria dos gatos eram adultos, confirmando com os dados de outros estudos, que a maior porcentagem desses vírus ocorre em gatos machos (Teixeira et al., 2007; Vicente Sobrinho et al., 2011). Isto é justificado devido o comportamento do macho, que se envolvem em brigas por território e acasalamento, facilitando assim a infecção, uma vez que o vírus se encontra presente na saliva, e é transmitido por mordidas (Greene et al., 1993). De acordo com Levy et al. (2008), as taxas mais altas de infecção são encontradas em gatos adultos machos de vida livre com acesso à rua, o que corrobora com os resultados desta pesquisa (Ravazzolo \& Costa, 2007). Os resultados positivos obtidos foram de maior ocorrência em gatos adultos. No entanto, uma vez que no nosso estudo consideramos adultos todos os gatos a partir de um ano é impossível verificar neste estudo se a ocorrência é maior após os seis anos de idade, como referido na bibliografia consultada (Barr, 1996).

Diversos autores relataram que a transmissão por FeLV é facilitada pelo comportamento entre os animais e alta densidade populacional (Coelho et al., 2011; Levy et al., 2008; Spada et al., 2016). Little et al. (2009) observaram que o risco de infecção pelo FIV era 3,43 vezes maior em animais que tinham acesso à rua. Também foi visto que o contato com o ambiente externo aumenta as chances de infecção pelo vírus em 4,3\% (Levy et al., 2008). Contudo essas citações comprovaram para essa pesquisa, que o acesso à rua é um fator muito relevante na propagação do FIV, dada a sua forma de transmissão (Greene et al., 1993). Os resultados sugerem que a procedência dos animais, neste caso, animais que eram errantes e foram adotados, e animais que sempre tiveram livre acesso à rua podem ser fatores importantes para a transmissão de FIV e FeLV. Foi observado nesta pesquisa que gatos que conviviam juntos á muito tempo na mesma casa, ambos apresentaram resultado positivo para FIV. Isso se deve ao fato, que o risco da infecção aumenta em gatos adultos, quando os animais convivem com gatos virêmicos, o que é facilmente observado em gatis ou em casas em que os animais se tornam positivos após anos de convívio com gatos infectado (Grant et al., 1980). Os animais positivos para o FIV deste estudo eram mestiços $(12,5 \%)$. Este resultados semelhantes aos observados por Vicente Sobrinho et al. (2011) no município de Araçatuba (SP), onde 88,2\% dos gatos infectados foram mestiços. Mas, um maior número de animais mestiços pode ser devido ao perfil da raça de gatos criados na região.

Quanto ao seguimento clínico, até à conclusão desta pesquisa os animais infectados com FIV e FeLV não manifestaram sinais clínicos destas doenças, o que está de acordo com Liem et al. (2013) que defende que a maioria dos animais infectados se mantém assintomáticos durante longos períodos de tempo.

O diagnóstico dessas retroviroses em gatos não pode se basear exclusivamente nas alterações clínicas dos pacientes, devendo ser baseado na demonstração de anticorpos anti-FIV e de antígenos do FeLV desses animais, pelo fato da infecção viral persistir mesmo o animal apresentando uma boa resposta imunológica (Bendinelli et al., 1995). Os testes imunocromatográficos disponíveis são utilizados para detecção qualitativa e simultânea dos anticorpos do vírus da FIV e antígenos virais da FeVL (Ravazzolo \& Costa, 2007). Este tipo de teste é considerado uma ferramenta muito útil para o diagnóstico veterinário por ser rápido, ser de fácil utilização sem necessidade de máquinas especializadas ou técnicos capacitados (Kim et al., 2014), além de ser econômico e de fácil interpretação (Hartmann et al., 2007). Apresentam alta sensibilidade e especificidade em gatos positivos para FIV (Hartmann et al., 2007; Levy et al., 2008) e valores de $96 \%$ de sensibilidade e $98 \%$ de especificidade respectivamente semelhante ao ELISA para FeLV (Hartmann, 2012; Kim et al., 2014). É bastante utilizado na prática clínica, para obter um diagnóstico precoce (Hartmann et al., 2007). Apesar das diversas metodologias 
utilizadas para testar os animais, os resultados obtidos podem ser considerados confiáveis, como demonstrado por Westman et al. (2015). Estes autores compararam a eficácia do ensaio imunoenzimático e o ensaio imunocromatográfico, e os resultados mostraram que os testes foram semelhantes e precisos para detectar a infecção por FIV e FeLV (Westman et al., 2015). A realização de testes de diagnóstico como triagem na rotina clínica é muito importante, e deve ser feito em todos os gatos com idade acima dos 6 meses, como uma forma de prevenção da ocorrência e infecção por esses vírus (Hartmann, 2012; Hartmann et al., 2007).

\section{Conclusão}

Os resultados obtidos mostram que FIV e FeLV são duas doenças de extrema importância, pelo fato de se disseminarem facilmente entre os felinos, por isso o teste imune ensaio cromatográfico na rotina clínica e uma ótima ferramenta para o diagnóstico precoce dessas infecções, para a implementação de medidas de prevenção e controle, contribuindo para a diminuição da ocorrência desses vírus na população felina.

\section{Referências bibliográficas}

Arjona, A., Escolar, E., Soto, I., Barquero, N., Martin, D. \& Gomez-Lucia, E. (2000). Seroepidemiological survey of infection by feline leukemia virus and immunodeficiency virus in Madrid and correlation with some clinical aspects. Journal of Clinical Microbiology, 38(9):34483449.

Barr, M. C. (1996). FIV, FeLV, and FIPV: interpretation and misinterpretation of serological test results. Paper presented at the Seminars in veterinary medicine and surgery (small animal).

Barros, V. R., Bezerra, J. A. B., Bochnakian, M. S., Paula, V. V. \& Filgueira, K. D. (2017). Epidemiology of feline immunodeficiency virus and feline leukemia virus in a veterinary teaching hospital. Revista Brasileira de Higiene e Sanidade Animal, 11(2):151-160.

Bendinelli, M., Pistello, M., Lombardi, S., Poli, A., Garzelli, C., Matteucci, D., . . Tozzini, F. (1995). Feline immunodeficiency virus: an interesting model for AIDS studies and an important cat pathogen. Clinical Microbiology Reviews, 8(1):87-112.

Blanco, K., Prendas, J., Cortes, R., Jimenez, C. \& Dolz, G. (2009). Seroprevalence of viral infections in domestic cats in Costa Rice. Journal of Veterinary Medical Science, 71(5):661-663.

Caldas, A. P. F., Leal, É. d. S., Silva, E. F. A. \& Ravazzolo, A. P. (2000). Detecção do provírus da imunodeficiência felina em gatos domésticos pela técnica de reação em cadeia da polimerase. Pesquisa Veterinaria Brasileira, 20(1):20-25.

Caxito, F. A., Magalhães-Coelho, F. \& Pinto, F. F. (2003). Study of feline immunodeficiency virus (FIV) in Minas Gerais by nested PCR-RFLP analysis of the gag gene. Virus Rewiew \& Research, 14209.

Coelho, F. M., Bomfim, M. R. Q., Caxito, F. A., Ribeiro, N. A., Luppi, M. M., Costa, É. A., .. Resende, M. (2008). Naturally occurring feline leukemia virus subgroup A and B infections in urban domestic cats. Journal of General Virology, 89(11):2799-2805.

Coelho, F. M., Maia, M. Q., Luppi, M. M., Costa, E. A., Luiz, A. P. M. F., Ribeiro, N. A., . . Resende, M. (2011). Ocorrência do vírus da leucemia felina em Felis cattus em Belo Horizonte. Arquivo Brasileiro de Medicina Veterinária e Zootecnia, 63(3):778-783.

Costa, U. M., Reischak, D., Schmitt, A. C., Renck, L., Oliveira, E. S. \& Ferreiro, L. (2000). Detection of feline leukemiavirus (FeLV) antigen from 1992 to june 2000 by indirect immunofluorescence test in Porto Alegre, Rio Grande do Sul, Brasil. Journal of the Brazilian Society for Virology, 5(1):9495.

Diehl, L. J. \& Hoover, E. A. (1992). Early and progressive helper T-cell dysfunction in feline leukemia virus-induced immunodeficiency. Journal of Acquired Immune Deficiency Syndromes, 5(12):11881194. 
Dorny, P., Speybroeck, N., Verstraete, S., Baeke, M., De Becker, A., Berkvens, D. \& Vercruysse, J. (2002). Serological survey Toxoplasma gondii of a on feline immunodeficiency virus and feine leukaemia virus in urban stray cats in Belgium. Veterinary Record, 151(21):626-629.

Duarte, A., Castro, I., Fonseca, P. I. M., Almeida, V., Carvalho, L. M. M., Meireles, J., . . Vaz, Y. (2010). Survey of infectious and parasitic diseases in stray cats at the Lisbon Metropolitan Area, Portugal. Journal of Feline Medicine and Surgery, 12441-446.

Grant, C. K., Essex, M., Gardner, M. B. \& Hardy, W. D. (1980). Natural feline leukemia virus infection and the immune response of cats of different ages. Cancer Research, 40(3):823-829.

Greene, C. E., Samperio, J. O. \& Gómez, J. P. (1993). Enfermedades infecciosas: Perros y gatos. São Paulo: Editora Interamericana.

Hartmann, K. (2012). Clinical aspects of feline retroviruses: a review. Viruses, 4(11):2684-2710.

Hartmann, K., Griessmayr, P., Schulz, B., Greene, C. E., Vidyashankar, A. N., Jarrett, O. \& Egberink, H. F. (2007). Quality of different in-clinic test systems for feline immunodeficiency virus and feline leukaemia virus infection. Journal of Feline Medicine and Surgery, 9(6):439-445.

Junqueira-Jorge, J. (2005). Estudo dos fatores de risco da leucemia viral felina no munícipio de São Paulo. PhD, Universidade de São Paulo, São Paulo, Brasil.

Kim, W.-S., Chong, C.-K., Kim, H.-Y., Lee, G.-C., Jeong, W., An, D.-J., . . . Lee, Y.-K. (2014). Development and clinical evaluation of a rapid diagnostic kit for feline leukemia virus infection. Journal of Veterinary Science, 15(1):91-97.

Levy, J., Crawford, C., Hartmann, K., Hofmann-Lehmann, R., Little, S., Sundahl, E. \& Thayer, V. (2008). American Association of Feline Practitioners' feline retrovirus management guidelines. Journal of Feline Medicine and Surgery, 10(3):300-316.

Levy, J. K., Scott, H. M., Lachtara, J. L. \& Crawford, P. C. (2006). Seroprevalence of feline leukemia virus and feline immunodeficiency virus infection among cats in North America and risk factors for seropositivity. Journal of the American Veterinary Medical Association, 228(3):371-376.

Liem, B. P., Dhand, N. K., Pepper, A. E., Barrs, V. R. \& Beatty, J. A. (2013). Clinical findings and survival in cats naturally infected with feline immunodeficiency virus. Journal of Veterinary Internal Medicine, 27(4):798-805.

Little, S., Sears, W., Lachtara, J. \& Bienzle, D. (2009). Seroprevalence of feline leukemia virus and feline immunodeficiency virus infection among cats in Canada. The Canadian Veterinary Journal, 50(6):644-648.

Lutz, H. (1990). Feline retroviruses: a brief review. Veterinary Microbiology, 23(1-4):131-146.

Meinerz, A. R. M., Antunes, T. Á., Souza, L. L., Nascente, P. S., Faria, R. O., Cleff, M. B., . . Schuch, L. F. D. (2010). Frequência do virus da leucemia felina (VLFe) em felinos domésticos (Felis catus) semidomiciliados nos municípios de Pelotas e Rio Grande. Ciência Animal Brasileira, 11(1):90-93.

Nelson, R. W. \& Couto, C. G. (2015). Medicina interna de pequenos animais. Amsterdan: Elsevier Editora.

Ogilvie, G. K., Tompkins, M. B. \& Tompkins, W. A. F. (1988). Clinical and immunologic aspects of FeLV-induced immunosuppression. Veterinary Microbiology, 17(3):287-296.

Poffo, D. (2012). Infecção pelo vírus da imunodeficiência viral felina e leucemia viral em felídeos domésticos e silvestres atendidos no Hospital Veterinário da UFMT- Cuiabá- Brasil. Graduate, Universidade Federal de mato Grosso do Sul, Cuiabá, Mato Grosso do Sul.

Ravazzolo, A. P. \& Costa, U. (2007). Retroviroses. In F. E. F. (Ed.), Virologia Veterinária (pp. 811836). Santa Maria, Rio Grande do Sul: Editora da Universidade Fedral de Santa Maria.

Reche Junior, A., Hagiwara, M. K. \& Lucas, S. R. R. (1997). Clinical study of acquired immunodeficiency syndrome in domestic cats in São Paulo. Brazilian Journal Veterinary Research Animal Science, 34(3):152-155.

Solano, G., A., R. C., Iniesta, L., Quintana, J., Pastor, J., Espada, Y., . . Alberola, J. (2007). Crosssectional serosurvey of feline leishmaniasis in ecoregions around the Northwestern Mediterranean. American Journal of Tropical Medicine and Hygiene, 76(4):676-680. 
Souza, H. J. M., Teixeira, C. H. R. \& Graça, R. F. S. (2002). Estudo epidemiológico de infecções pelo vírus da leucemia e/ou imunodeficiência felina, em gatos domésticos do município do Rio de Janeiro. Clínica Veterinária, 3614-21.

Spada, E., Canzi, I., Baggiani, L., Perego, R., Vitale, F., Migliazzo, A. \& Proverbio, D. (2016). Prevalence of Leishmania infantum and co-infections in stray cats in northern Italy. Comparative Immunology, Microbiology and Infectious Diseases, 4553-58.

Teixeira, B. M., Rajão, D. S., Haddad, J. P., Leite, R. C. \& Reis, J. K. (2007). Ocorrência do vírus da imunodeficiência felina e do vírus da leucemia felina em gatos domésticos mantidos em abrigos no município de Belo Horizonte. Arquivo Brasileiro de Medicina Veterinária e Zootecnia, 59(4):939942.

Vicente Sobrinho, L. S., Vides, J. P., Braga, E. T., Gomes, A. D., Rossi, C. N. \& Marcondes, M. (2011). Sorofrequência de infecção pelo vírus da imunodeficiência felina e vírus da leucemia felina em gatos do município de Araçatuba, São Paulo. Brazilian Journal of Veterinary Research and Animal Science, 48(5):378-383.

Westman, M. E., Malik, R., Hall, E., Sheehy, P. A. \& Norris, J. M. (2015). Determining the feline immunodeficiency virus (FIV) status of FIV-vaccinated cats using point-of-care antibody kits. Comparative Immunology, Microbiology and Infectious Diseases, 4243-52.

Yilmaz, H., Ilgaz, A. \& Harbour, D. A. (2000). Prevalence of FIV and FeLV infections in cats in Istanbul. Journal of Feline Medicine \& Surgery, 2(1):69-70.

Recebido: 30 de janeiro, 2019.

Aprovado: 22 de fevereiro, 2019.

Publicado: 18 de março, 2019.

Licenciamento: Este artigo é publicado na modalidade Acesso Aberto sob a licença Creative Commons Atribuição 4.0 (CC-BY 4.0), a qual permite uso irrestrito, distribuição, reprodução em qualquer meio, desde que o autor e a fonte sejam devidamente creditados. 